\title{
AORTIC VALVE REPLACEMENT IN PATIENTS AGED EIGHTY YEARS AND OLDER: EARLY AND LONG-TERM RESULTS
}

Ajay Gehlot, MS, $\mathrm{MCh}^{*}$

Charles J. Mullany, MB, MS**

Duane Ilstrup, MS***

Hartzell V. Schaff, MD**

Thomas A. Orszulak, MD**

James J. Morris, MD**

Richard C. Daly, $\mathrm{MD}^{* *}$
We have studied 322 patients, 80 years of age or older, who underwent aortic valve replacement between June 1971 and December 1992. Two hundred six patients $(64 \%)$ have had surgery since the end of 1985 . Their mean age was 82.7 years (range 80 to 92 years). One hundred seventy-one (53\%) were male and most $(86 \%)$ were in New York Heart Association class III-IV. Fifty-seven patients $(18 \%)$ required admission to the coronary care unit before the operation. One hundred seventy-nine patients $(56 \%)$ underwent an urgent or emergency operation. Known cerebrovascular disease was present in 77 (24\% of patients), aortic stenosis in $79 \%$, aortic incompetence in 9\%, and combined stenosis and incompetence in $12 \%$. Associated procedures included bypass grafting in $139(43 \%)$, mitral valve replacement/repair in $20(6 \%)$, tricuspid valve repair in $6(2 \%)$, and aortic annular enlargement in $38(12 \%)$. Thirty patients $(9.3 \%)$ were undergoing reoperation. Hospital mortality was 44 of $322(13.7 \%)$. The median hospital stay was 11 days. On univariate analysis, significant predictors of hospital mortality were female sex, preoperative rest pain, New York Heart Association class III-IV, admission to the coronary care unit, heart failure, mitral valve disease, emergency/urgent operation, chronic obstructive pulmonary disease, bypass grafting, valve size, peripheral vascular disease, and ejection fraction less than 0.35 . On multivariate analysis the most important independent predictors of operative mortality were female gender ( $p=$ 0.0001 ), renal impairment ( $p=0.001)$, bypass grafting $(p=0.005)$, ejection fraction less than $0.35(p=0.01)$, and chronic obstructive pulmonary disease $(p=0.028)$. Age and year of operation did not influence mortality. Five-year survivals for all patients and for operative survivors were $60.2 \%$ $\pm 3.2 \%$ and $70.3 \% \pm 3.4 \%$, respectively. On univariate analysis, factors that adversely affected long-term survival were coronary bypass grafting ( $p=$ $0.007)$, more than two comorbidities $(p=0.02)$, male gender $(p=0.04)$, and ejection fraction less than $0.35(p=0.04)$. On multivariate analysis, no factor was consistently significant for long-term survival. At most recent clinical follow-up $85 \%$ were angina free and $82 \%$ were in class I-II. At least 92\% of patients, both at 1 year and at most recent clinical follow-up, believed they had significantly benefited from the operation: Conclusion: Risk factors for aortic valve replacement in octogenarians include female
From the Division of Cardiothoracic Surgery, Mayo Foundation, Mayo Clinic, Rochester, Minn.

Read at the Twenty-first Annual Meeting of The Western Thoracic Surgical Association, Coeur d'Alene, Idaho, June 21-24, 1995.

Received for publication June 21, 1995; revisions requested Sept. 21, 1995; revisions received Dec. 28, 1995; accepted for publication Jan. 3, 1996.

Address for reprints: Charles J. Mullany, MB, MS, Mayo Clinic, 200 First St., SW, Rochester, MN 55905.

\author{
${ }^{*}$ Fellow, Cardiothoracic Surgery. \\ ***: Consultant. \\ ***Associate in Biostatistics. \\ J Thorac Cardiovasc Surg 1996;111:1026-36 \\ Copyright (C) 1996 by Mosby-Year Book, Inc. \\ $0022-5223 / 96 \$ 5.00+0 \quad \mathbf{1 2 / 6 / 7 1 5 9 8}$
}


gender, unstable symptoms, poor ejection fraction, renal impairment, and bypass grafting. However, despite a hospital mortality higher than that reported for younger patients, the outlook for operative survivors is excellent, with good relief of symptoms and an expected survival normal for this particular age group. If possible, aortic valve replacement should be done before development of unstable symptoms. (J Thorac Cardiovasc Surg 1996;111:1026-36)

A ccording to the U.S. Bureau of Statistics, in 1995 the number of Americans aged 75 years or older was 14.5 million and by the year 2005 this figure is expected to rise to 17.1 million. ${ }^{1}$ Thus elderly persons constitute $6 \%$ of the population, and at least $46 \%$ are thought to have symptomatic cardiac disease. ${ }^{2}$ With this aging of the population and the greater use of noninvasive diagnostic techniques, particularly echocardiography with two-dimensional Doppler ultrasonography, the diagnosis of symptomatic aortic valve disease, particularly aortic stenosis, is becoming increasingly common. Although aortic valve replacement (AVR) has a higher risk in older patients, AVR is the only effective treatment for symptomatic aortic stenosis. Age alone is not a contraindication for this operation, inasmuch as several studies have shown that AVR in patients 80 years or older can be performed with an acceptable operative mortality and morbidity. ${ }^{3-12}$ However, the long-term outcome in these patients has not been documented. To analyze these issues further, we have reviewed our early and long-term results in patients aged 80 years and older who have undergone AVR at the Mayo Medical Center, Rochester, Minnesota, between June 1971 and December 1992.

\section{Methods}

Records of 322 patients who underwent AVR, with or without concomitant procedures, were reviewed. A total of 84 preoperative, operative, and postoperative variables were recorded. Follow-up information was obtained from all hospital survivors through clinic visits and annual letters. Between May and July 1994 all known survivors were sent a letter questionnaire. This was designed to determine general health status, presence or absence of chest pain, dyspnea or angina pectoris, postoperative New York Heart Association (NYHA) functional class, the overall effects of the operation, and quality of life. Any subsequent reoperation was also recorded. Questionnaires were also sent to the patient's local physician.

Coronary artery disease was defined as a reduction of vessel diameter by at least $50 \%$ in one view on coronary angiography. Stenosis to this degree in the left anterior descending system, circumflex system, or right coronary system was used for the criterion of single, double, or triple vessel disease. Stenosis of $50 \%$ or more in the left main coronary artery was described as double vessel disease in the absence of other coronary stenoses. Operative mortality was any death occurring within 30 days of the operation or death during the same hospital admission as the operation. Renal impairment was defined as a serum creatinine concentration of $1.5 \mathrm{mg} / \mathrm{dl}$ or more. Heart failure was determined by the presence of pulmonary congestion or opacities consistent with edema on chest roentgenograms.

Distribution for all relevant variables has been expressed either as percentages or as mean \pm standard deviation. The effects of nominal risk factors, such as presence of rest pain, on early mortality were evaluated univariately with $\chi^{2}$ tests or Fisher's exact test. The effects of continuous variables, such as age and serum creatinine concentration, were univariately evaluated with two-sample $t$ tests or with Wilcoxon rank sum tests when necessary. Combinations of risk factors were multivariately evaluated with multiple logistic regression models. Survivorship to death, for all patients and for all hospital survivors, was estimated by means of the Kaplan-Meier method. To assess separately those risk factors related to late survival as distinct from operative deaths, we analyzed only hospital survivors. Nominal risk factors for survival were assessed with log-rank tests. Continuous measurable risk factors, such as age, and combinations of risk factors, both nominal and continuous, were evaluated with Cox's proportional hazards models. A $p$ value $<0.05$ was considered statistically significant.

\section{Results}

The study comprised 171 men (53\%) and 151 women. Their mean age was 82.7 years (range 80 to 92 years). The majority of patients have undergone surgery since 1986. The distribution of patients undergoing surgery during three different time periods was as follows: $16(5 \%)$ in 1971 to 1977,100 (31\%) in 1978 to 1985 ; and $206(64 \%)$ in 1986 to 1992.

Symptoms included dyspnea (310, 96\%), angina pectoris $(134,42 \%)$, and syncope $(88,27 \%)$. A diagnosis of heart failure was made in $197(61 \%)$ patients. A total of $276(86 \%)$ patients were considered to be in NYHA class III-IV. Only seven patients had no or minimal symptoms. Two hundred fifty-four (79\%) patients were considered to have aortic stenosis, 28 (9\%) had mixed aortic stenosis 
Table I. Preoperative comorbidities in 322 patients aged 80 years or older undergoing $A V R$

\begin{tabular}{lrr}
\hline & $n$ & $\%$ \\
\hline Hypertension & 163 & 51 \\
Previous myocardial infarction & 48 & 15 \\
Diabetes mellitus & 35 & 11 \\
Renal impairment* & 75 & 23 \\
Cerebrovascular disease & 77 & 24 \\
$\quad$ Asymptomatic & 26 & \\
TIA & 17 & \\
CVA & 28 & \\
CEA & 2 & \\
CEA/CVA & 4 & \\
Chronic obstructive airway disease & 65 & 20 \\
Peripheral vascular disease & 37 & 12 \\
Abdominal aortic aneurysm & 22 & 7 \\
\hline TLA, temporary ischemic accident; CVA, cerebrovascular accident; CEA, \\
carotid endarterectomy. \\
${ }^{*}$ Creatinine concentration $\geq 1.5 \mathrm{mg} / \mathrm{dl}$.
\end{tabular}

and regurgitation, and $39(12 \%)$ had aortic insufficiency. Preoperative comorbidities are listed in Table I. Seventy-seven (24\%) patients had known cerebrovascular disease. Of these, 34 (11\%) had had cerebrovascular accidents or had undergone carotid endarterectomy (or both). Twenty-two (7\%) of the patients had known or resected abdominal aneurysms. One hundred forty-three (44\%) patients had an elective operation, $163(51 \%)$ had an urgent operation because of angina or heart failure that did not respond to the usual clinical measures, and 16 (5\%) patients required an emergency operation for hemodynamic deterioration. Only one patient required an intraaortic balloon pump before the operation. Men and women differed significantly with regard to certain clinical features (Table II). Whereas men were more likely to have coronary artery disease, a history of myocardial infarction, renal impairment, and a need for coronary artery bypass grafting (CABG), women tended to have heart failure and required smaller prostheses. Women were also more likely to reside in the local community.

Hemodynamic and angiographic studies. Preoperative cardiac catheterization was performed in 180 $(56 \%)$ patients and echocardiography in $220(68 \%)$. We do not perform invasive hemodynamic studies of the valve if clinical symptoms, physical examination, and two-dimensional echocardiography are all indicative of aortic valve disease. ${ }^{13} \mathrm{~A}$ summary of the hemodynamic data is listed in Table III. Three hundred $(93 \%)$ patients had an estimate of left ventricular ejection fraction by either left ventricu- lography or echocardiography. Of these, $64(21 \%)$ had an ejection fraction of less than 0.35 . Coronary angiography was performed in $295(92 \%)$ patients. Significant coronary artery disease was present in $173(59 \%)$ of these patients. Sixty-eight had single vessel disease, 40 had two vessel disease, and 65 had three vessel disease. Twenty-two patients had left main disease.

Previous operation. Thirty patients $(9 \%)$ had undergone a previous cardiac operation $77 \pm 42.6$ months earlier (Table IV). Of these, 21 had AVR or decalcification of the valve. A further 10 patients underwent percutaneous balloon valvuloplasty $14 \pm$ 17.0 months before the definitive aortic valve operation.

Operation. All patients underwent AVR. In addition, $139(43 \%)$ patients had concomitant CABG, the left internal thoracic artery being used in 39 $(28 \%)$ instances. In $38(11.8 \%)$ patients the aortic anulus was enlarged with a pericardial patch. Other procedures are listed in Table $\mathrm{V}$. The majority of patients $(287,89 \%)$ received either a porcine or pericardial bioprosthesis. Three patients received a homograft, and $32(10 \%)$ patients had a mechanical prosthesis.

Perioperative mortality. Death occurred in 44 patients $(13.7 \%)$ (Table VI). Causes of death were as follows: low cardiac output or myocardial infarction, or both, 21; multiorgan failure, 11; respiratory failure, 4; sepsis, 2; renal failure, 1 ; cerebrovascular accident, 4; and sudden unexpected death, 1 . On univariate analysis, female gender, rest pain, advanced NYHA class, heart failure, urgency of the operation, mitral valve disease, ejection fraction less than 0.35 , admission to the coronary care unit, renal impairment, chronic obstructive pulmonary disease, peripheral vascular disease, more than two comorbidities, $\mathrm{CABG}$, and valve size were important determinants of hospital mortality. However, on multivariate analysis, female gender $(p=0.0001)$, renal impairment $(p=0.001), \mathrm{CABG}(p=0.005)$, ejection fraction less than $0.35(p=0.01)$, and chronic obstructive pulmonary disease $(p=0.028)$ remained significantly related to hospital death. Age, year of operation, myocardial infarction, reoperative surgery, diabetes, coexistence of cerebrovascular disease, and distance traveled to the Mayo Clinic, which is a measure of referral bias, were not related to hospital mortality. Although patients with coronary artery disease had a higher mortality than those without coronary artery disease, this difference was not statistically significant. 
Table II. Gender differences in 322 patients aged $>80$ years or older undergoing AVR

\begin{tabular}{|c|c|c|c|c|c|}
\hline & \multicolumn{2}{|c|}{ Male } & \multicolumn{2}{|c|}{ Female } & \multirow[b]{2}{*}{ p Value } \\
\hline & $n$ & $\%$ & $n$ & $\%$ & \\
\hline Coronary artery disease* & 107 & 67 & 66 & 49 & 0.001 \\
\hline Myocardial infarction & 31 & 18 & 17 & 11 & 0.08 \\
\hline Renal impairment & 66 & 39 & 31 & 21 & 0.001 \\
\hline $\mathrm{CABG}$ & 87 & 51 & 52 & 34 & 0.003 \\
\hline Heart failure & 97 & 57 & 100 & 66 & 0.08 \\
\hline Residence $>60$ miles from Mayo Clinic & 130 & 77 & 85 & 56 & 0.001 \\
\hline Valve size $<23 \mathrm{~mm}$ & 30 & 18 & 113 & 75 & 0.001 \\
\hline
\end{tabular}

*A total of 295 patients underwent coronary angiography.

Table III. Hemodynamic data in 322 patients aged 80 years or older undergoing $A V R$

\begin{tabular}{lcc}
\hline & $n$ & Mean $\pm S D$ \\
\hline EF* $^{*}$ & & \\
$\quad$ Echo & 220 & $50.4 \% \pm 16.5 \%$ \\
$\quad$ Cath & 128 & $52.6 \% \pm 13.7 \%$ \\
EF <35\% (echo or cath) & $64(21 \%)$ & \\
LVEDP & 180 & $27.0 \pm 8.8 \mathrm{~mm} \mathrm{Hg}$ \\
Mean gradient $\dagger$ & & \\
$\quad$ Echo & 153 & $57.8 \pm 20.3 \mathrm{~mm} \mathrm{Hg}$ \\
Cath & 172 & $59.5 \pm 25.5 \mathrm{~mm} \mathrm{Hg}$ \\
AVA $\dagger$ & & \\
Echo & 146 & $0.6 \pm 0.2 \mathrm{~cm}^{2}$ \\
Cath & 141 & $0.5 \pm 0.2 \mathrm{~cm}^{2}$
\end{tabular}

$E F$, ejection fraction; Echo, echocardiography; Cath, catheterization; $L V E D P$, left ventricular end-diastolic pressure; $A V A$, aortic valve area.

*Ejection fraction was estimated by echocardiography and/or left ventriculography in 300 patients.

$\dagger$ Patients with aortic stenosis or mixed aortic stenosis and regurgitation.

Postoperative morbidity. The median stay in the hospital after the operation was 11 days. Twenty-one patients ( $7 \%$ ) had hospital stays of more than 30 days. Significant postoperative complications, apart from atrial arrhythmias, occurred in $172(53 \%)$ patients. These complications are listed in Table VII. Twentyseven patients $(8.4 \%)$ had a cerebrovascular accident. Of these, eight recovered completely, five were left with residual defects, and 14 died. Of these 14 deaths, four were thought to be directly related to the stroke. The presence of diabetes, known cerebrovascular disease, peripheral vascular disease, or a preoperative abdominal aneurysm was not related to the development of a postoperative stroke.

Long-term results. The mean follow-up time was 46 months, the longest being 15.4 years. Among the 278 hospital survivors, there have been 120 subsequent deaths. Four patients $(1.4 \%)$ have been lost to follow-up since discharge from the hospital. A further six patients have had follow-up for less than 1 year.
Table IV. Previous operations in 30 of 322 patients aged 80 years or older undergoing $A V R$

$\begin{array}{ll}\text { AVR } & 5 \\ \text { AVR + CABG } & 6 \\ \text { AVR + MVR } & 1 \\ \text { AV decalcification } & 1 \\ \text { AV decalcification + CABG } & 8 \\ \text { MVR } & 2 \\ \text { CABBG } & 7\end{array}$

$A V R$, Aortic valve replacement; $C A B G$, coronary artery bypass grafting $M V R$, mitral valve replacement; $A V$, aortic valve.

Table V. Operative procedures in 322 patients aged 80 years or older undergoing $A V R$

\begin{tabular}{lc}
\hline AVR & 162 \\
AVR + CABG & 136 \\
AVR + MVR & 8 \\
AVR + MVR + CABG & 2 \\
AVR + MVR + tricuspid annuloplasty & 4 \\
AVR + MV repair + CABG & 1 \\
AVR + MV repair + tricuspid annuloplasty & 1 \\
AVR + MV repair & 4 \\
AVR + tricuspid annuloplasty & 1 \\
AVR + pericardectomy & 1 \\
AVR + replacement of ascending aorta and arch & 1 \\
AVR + LV apex-innominate artery conduit & 1 \\
Aortic annular enlargement & $38(11.8 \%)$ \\
Septal myectomy & 8
\end{tabular}

$A V R$, Aortic valve replacement; $C A B G$, coronary artery bypass grafting; $M V$, mitral valve; $M V R$, mitral valve replacement; $L V$, left ventricle.

The 1 - and 5-year survivals ( \pm standard error of the mean) of all patients were $83.3 \% \pm 2.1 \%$ and $60.2 \% \pm 3.2 \%$, respectively. For operative survivors, the corresponding survivals were $96.7 \% \pm 1.1 \%$ and $70.3 \% \pm 3.4 \%$, respectively (Fig. 1 ). The 5 -year mortality of a population matched for age and sex is $59.0 \% \pm 3.4 \%(p=0.057)$. On univariate analysis, the following factors were significantly related to the long-term survival of those patients who left the hospital: gender (male: 5 years, $66.3 \% \pm 4.6 \%$; 
Table VI. Operative mortality in 322 patients aged 80 years or older undergoing AVR

\begin{tabular}{|c|c|c|c|c|c|c|c|}
\hline \multirow[b]{2}{*}{ Clinical features } & \multirow[b]{2}{*}{$n$} & \multicolumn{2}{|c|}{ Mortality } & \multicolumn{2}{|c|}{ Initial probability } & \multicolumn{2}{|c|}{ Final probability } \\
\hline & & $n$ & $\%$ & $\chi^{2}$ & $p$ & $\chi^{2}$ & $p$ \\
\hline Male & 171 & 16 & 9.4 & & & & \\
\hline Female & 151 & 28 & 18.5 & 5.7 & 0.02 & 15.5 & 0.0001 \\
\hline \multicolumn{8}{|l|}{ Year of operation } \\
\hline 1971-1985 & 116 & 16 & 13.8 & & & & \\
\hline 1986-1991 & 206 & 28 & 13.6 & 0.02 & NS & & \\
\hline NYHA class I-II & 46 & 1 & 2.2 & & & & \\
\hline NYHA class III-IV & 276 & 43 & 15.6 & 6.0 & 0.01 & & \\
\hline \multicolumn{8}{|l|}{ Rest pain } \\
\hline No & 291 & 33 & 11.3 & & & & \\
\hline Yes & 31 & 11 & 35.5 & 13.8 & 0.001 & & \\
\hline \multicolumn{8}{|l|}{$\mathrm{CCU}$} \\
\hline No & 265 & 26 & 9.8 & & & & \\
\hline Yes & 57 & 18 & 31.6 & 18.8 & 0.001 & & \\
\hline \multicolumn{8}{|l|}{ Heart failure } \\
\hline No & 125 & 10 & 8.0 & & & & \\
\hline Yes & 197 & 34 & 17.3 & 5.6 & 0.02 & & \\
\hline \multicolumn{8}{|l|}{ Mitral valve disease } \\
\hline No & 277 & 32 & 11.6 & & & & \\
\hline Yes & 45 & 12 & 26.7 & 7.5 & 0.006 & & \\
\hline \multicolumn{8}{|l|}{$\mathrm{EF}<0.35$} \\
\hline No & 236 & 23 & 9.8 & & & & \\
\hline Yes & 64 & 16 & 25.0 & 10.4 & 0.001 & 6.3 & 0.012 \\
\hline \multicolumn{8}{|l|}{ MI } \\
\hline No & 274 & 34 & 12.4 & & & & \\
\hline Yes & 48 & 10 & 20.8 & 2.5 & NS & & \\
\hline \multicolumn{8}{|l|}{$\mathrm{CAD}$} \\
\hline No & 122 & 12 & 9.8 & & & & \\
\hline Yes & 173 & 29 & 16.8 & 2.9 & NS & & \\
\hline \multicolumn{8}{|l|}{ CABG } \\
\hline No & 183 & 19 & 10.4 & & & & \\
\hline Yes & 139 & 25 & 18.0 & 39 & 0.05 & 8.0 & 0.005 \\
\hline \multicolumn{8}{|l|}{ Reoperation } \\
\hline No & 292 & 38 & 13.0 & & & & \\
\hline Yes & 30 & 6 & 20.0 & 1.1 & NS & & \\
\hline \multicolumn{8}{|l|}{ Urgent operation } \\
\hline No & 143 & 8 & 5.6 & & & & \\
\hline Yes & 179 & 36 & 20.1 & 14.2 & 0.001 & & \\
\hline \multicolumn{8}{|l|}{ Creatinine $\geq 1.5 \mathrm{mg} / \mathrm{dl}$} \\
\hline No & 225 & 21 & 9.3 & & & & \\
\hline Yes & 97 & 23 & 23.7 & 11.9 & 0.001 & 10.6 & 0.001 \\
\hline Diabetes & & & & & & & \\
\hline No & 287 & 36 & 12.5 & & & & \\
\hline Yes & 35 & 8 & 22.9 & 2.8 & NS & & \\
\hline PVD & & & & & & & \\
\hline No & 285 & 33 & 11.6 & & & & \\
\hline Yes & 37 & 11 & 29.7 & 9.1 & 0.002 & & \\
\hline COPD & & & & & & & \\
\hline No & 257 & 30 & 11.7 & & & & \\
\hline Yes & 65 & 14 & 21.5 & 4.3 & 0.04 & 4.9 & 0.028 \\
\hline CVD & & & & & & & \\
\hline No & 245 & 31 & 12.7 & & & & \\
\hline Yes & 77 & 13 & 16.9 & 0.9 & NS & & \\
\hline More than two comorbic & & & & & & & \\
\hline No & 193 & 17 & 8.8 & & & & \\
\hline Yes & 129 & 27 & 20.9 & 9.6 & 0.002 & & \\
\hline
\end{tabular}


Table VI. Continued

\begin{tabular}{|c|c|c|c|c|c|c|c|}
\hline \multirow[b]{2}{*}{ Clinical features } & \multirow[b]{2}{*}{$n$} & \multicolumn{2}{|c|}{ Mortality } & \multicolumn{2}{|c|}{ Initial probability } & \multicolumn{2}{|c|}{ Final probability } \\
\hline & & $n$ & $\%$ & $x^{2}$ & $p$ & $x^{2}$ & $p$ \\
\hline \multicolumn{8}{|c|}{ More than 60 miles from clinic } \\
\hline No & 105 & 18 & 17.1 & & & & \\
\hline Yes & 215 & 26 & 12.1 & 1.5 & NS & & \\
\hline \multicolumn{8}{|l|}{ Valve size (mm) } \\
\hline$<20$ & 39 & 9 & 23.1 & & & & \\
\hline $21+22$ & 104 & 17 & 16.4 & & & & \\
\hline 23 & 128 & 15 & 11.7 & & & & \\
\hline $25+27$ & 48 & 2 & 4.2 & 7.72 & 0.05 & & \\
\hline
\end{tabular}

NYHA, New York Heart Association; $C C U$, coronary care unit; $E F$, ejection fraction; $M I$, myocardial infarction; $C A D$, coronary artery disease; $C A B G$, coronary artery bypass grafting; $P V D$, peripheral vascular disease; $C O P D$, chronic obstructive pulmonary disease; $C V D$, cerebrovascular disease, $N S$, not significant.

female: 5 years, $75.7 \% \pm 4.8 \% ; p=0.04)$, CABG $(p=0.007)$, presence of more than two comorbidities $(p=0.02)$, and ejection fraction less than 0.35 $(p=0.04)$ (Figs. 2 to 5). No difference in survival was noted between patients 82 years old or less and those older than 82 years. When the aforementioned significant factors were entered into a Cox regression analysis, it was not possible to derive a consistent multivariate model to predict risk factors influencing survival.

Quality of life. Information regarding the 1-year clinical status was available in 255 of the 278 hospital survivors. Two hundred thirty-six patients $(93 \%)$ reported no angina. One hundred fifteen (45\%) still had some dyspnea. Only six patients (3\%) were considered to be in NYHA class III-IV. However, this improvement did not persist. At the most recent clinical follow-up examination (mean of 47 months), 47 patients $(18 \%)$ were considered to be in NYHA class III-IV. Of the 254 patients who responded to the question as to whether they had benefited from the operation, $5 \%$ thought that their condition was unchanged, $3 \%$ thought that they were in worse condition, and $92 \%$ thought that they were in better condition.

Three patients had another cardiac operation. Two operations were for perivalvular regurgitation and the third for a leaflet perforation of a previously placed Carpentier-Edwards porcine bioprosthesis (Baxter Healthcare Corp., Edwards Div., Santa Ana, Calif.).

\section{Discussion}

With the aging of the population, elderly patients are being increasingly referred to and being accepted by the cardiac surgeon for the surgical management of aortic stenosis. This trend has also been accentuated by the broader use of two-dimensional echocardiography with Doppler ultrasonography ${ }^{13}$
Table VII. Postoperative complications in 322 patients aged 80 years or older undergoing $A V R$

\begin{tabular}{lrr}
\hline \multicolumn{1}{c}{ Complications } & $n$ & $\%$ \\
\hline Low cardiac output & 75 & 23 \\
Postoperative IABP & 18 & 6 \\
Prolonged ventilation $(>72 \mathrm{hr})$ & 56 & 17 \\
Reexploration for bleeding & 15 & 5 \\
Cerebrovascular accident & 27 & 8 \\
Permanent pacemaker & 35 & 11 \\
Renal failure & 18 & 6 \\
Mediastinitis & 2 & 1
\end{tabular}

$I A B P$, Intraaortic balloon pump.

for the noninvasive evaluation of valvular heart disease and by the greater willingness of referring cardiologists to examine elderly patients with angina primarily with a view to myocardial revascularization. Although $43 \%$ of our patients underwent combined AVR and $C A B G$, we do not have information on how many were primarily evaluated for myocardial ischemia and were found to have incidental aortic stenosis. In previous studies we $\mathrm{e}^{14}$ have shown that patients undergoing combined AVR and CABG have lesser degrees of aortic stenosis than those with isolated aortic stenosis.

AVR remains the only effective treatment for aortic stenosis. Previous studies of natural history have shown a poor outcome for patients with severe aortic stenosis who were treated medically. ${ }^{15,16} \mathrm{Al}-$ though some hoped that percutaneous balloon valvuloplasty would be a successful treatment for aortic stenosis in elderly patients, both the medium- and long-term results of this therapy have been extremely disappointing. Symptoms have recurred within 1 year of treatment in most patients and have necessitated subsequent surgery. ${ }^{17,18}$ Aortic balloon valvuloplasty is no longer covered by Medicare. In addition, aortic valve decalcification has not been 


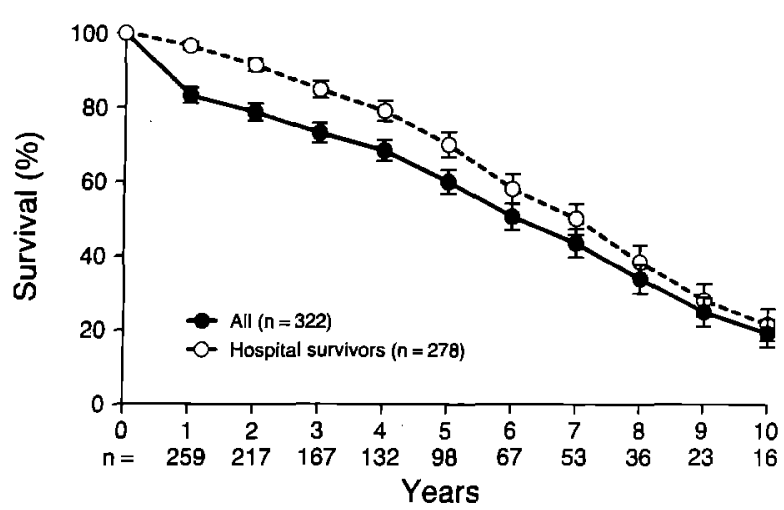

Fig. 1. Survival curve of all 322 patients and 278 hospital survivors aged 80 years and older undergoing AVR.

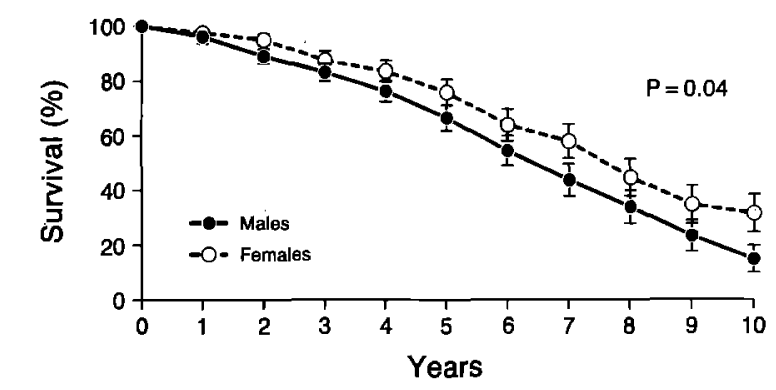

$\begin{array}{llllllllllll}\text { Males } & 155 & 144 & 118 & 91 & 72 & 53 & 33 & 24 & 16 & 11 & 7\end{array}$

Fig. 2. Effect of gender on survival in 278 hospital survivors aged 80 years and older undergoing AVR. Number at risk shown by year.

effective in the long term, with many patients returning for further surgery for either recurrent aortic stenosis or significant aortic regurgitation. ${ }^{19}$

We believe that most elderly patients with significant symptomatic aortic stenosis are candidates for AVR. Clearly comorbid disease, such as renal impairment and chronic obstructive pulmonary disease, increases operative risk. However, we do not have any information on how many patients were turned down for, or declined, surgery. Serious life-threatening illness such as disseminated malignant disease, severe disability from a cerebrovascular accident, or marked infirmity would be contraindications for surgery. In these elderly patients, the decision to operate needs to be individualized, with the patient and family aware of the risks and benefits of the operation. Our results clearly show that the majority of patients do well, with the 5-year survival far better than that for untreated symptomatic aortic stenosis.

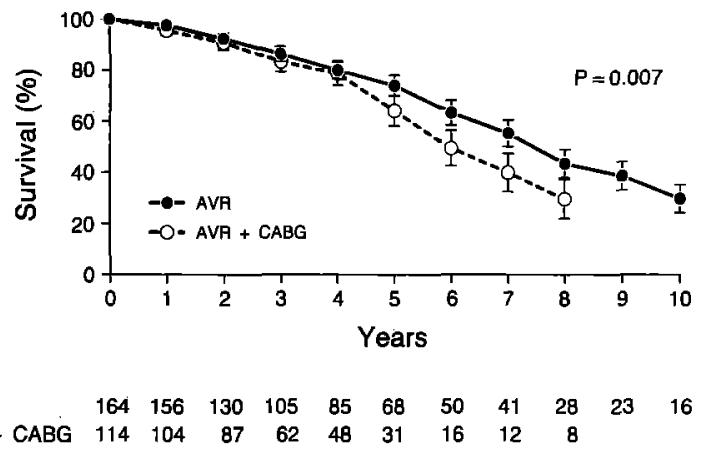

Fig. 3. Effect of CABG on survival in 278 hospital survivors aged 80 years and older undergoing AVR. Number at risk shown by year.

A less common but more controversial problem is the management of significant aortic stenosis in the patient who has no symptoms. In such circumstances the risk of sudden death as the first clinical manifestation of aortic stenosis is rare ${ }^{20}$ Again, treatment decisions need to be individualized, but most patients without symptoms can be observed unless the aortic stenosis is severe enough to be of concern. A patient with an aortic valve area less than $0.7 \mathrm{~cm}^{2}$ needs to be seriously considered for surgery, even if free of symptoms.

Patients in whom coronary artery disease is the primary problem may have mild aortic stenosis, which by itself would not necessarily warrant an operation. The decision whether to replace the aortic valve in such circumstances is difficult. However, we believe that the surgeon should favor AVR, particularly inasmuch as AVR after previous CABG carries a substantial mortality. In a recent review of our own experience, the operative mortality for AVR after previous CABG was $16.2 \%$.*

Several points in the operative technique for AVR in elderly patients need emphasis. The cardiac tissues are often friable and careful handling of the heart during all aspects of the operation is essential. The small aortic root, particularly in the female patient, may need to be enlarged to accommodate a valve of adequate size. In most instances we would avoid placement of a $19 \mathrm{~mm}$ tissue valve and instead enlarge the aortic root with a pericardial patch. ${ }^{21,22}$ Not only does this allow placement of a valve one size larger, but it may also facilitate placement of the

*Odell JA, Mullany CJ, Schaff HV, Orszulak TA, Morris JJ. Aortic valve replacement after previous coronary artery bypass grafting. Unpublished data. 


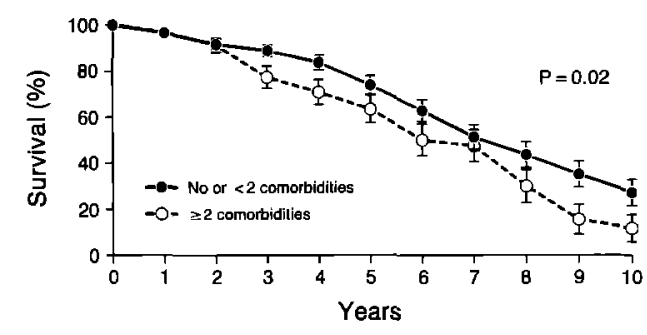

$\begin{array}{llllllllllll}\text { No or }<2 \text { comorbidities } & 176 & 163 & 145 & 117 & 93 & 68 & 47 & 35 & 26 & 19 & 13\end{array}$ $\begin{array}{llllllllllll}\geq 2 \text { comorbidities } & 102 & 96 & 72 & 50 & 40 & 31 & 20 & 18 & 10 & 4 & 3\end{array}$

Fig. 4. Effect of comorbid disease on survival in 278 hospital survivors aged 80 years and older undergoing AVR. Number at risk shown by year.

valve, including closure of the aortic root. Most patients should receive a tissue valve inasmuch as the long-term durability of such valves in this age group is excellent and the need for long-term anticoagulation is avoided. If the patient requires multiple coronary artery grafts, use of the internal thoracic artery is helpful because this avoids an additional aortic anastomosis.

The overall operative mortality in this series is comparable with those already reported in other series $\left(4.2 \%^{10} ; 9.4 \%{ }^{6} ; 12.7 \%^{4} ; 17.5 \%^{3}\right.$; and $\left.28 \%^{5}\right)$. The most important factors related to mortality, apart from gender, appear to be related to severity of symptoms, urgency of the operation, ejection fraction, and coexisting disease such as renal impairment. Patients in NYHA class I-II had the lowest mortality (2.2\%) and patients admitted to the hospital for elective surgery had a mortality of $5.6 \%$. These observations suggest that surgery, if possible, should be undertaken before the development of unstable symptoms or heart failure necessitating urgent admission to the hospital. Once a decision has been made to proceed, the operation should be undertaken without undue delay. The higher mortality in women has been noted previously. ${ }^{23,24}$ Recent data from our own institution also demonstrated the importance of female gender in mortality. ${ }^{24}$ However, the cause of this excessive mortality is not clear, particularly inasmuch as coronary artery disease, prior myocardial infarction, and renal disease are less prevalent in women than men. Small valve size $(<23 \mathrm{~mm})$ may be important, because this is far more prevalent in women. Patients receiving small valves had a significantly higher mortality than those receiving valves larger than $23 \mathrm{~mm}$.

Cerebrovascular accidents continue to be impor-

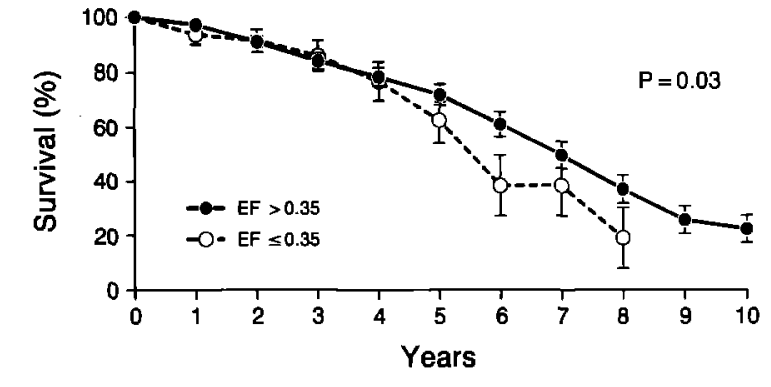

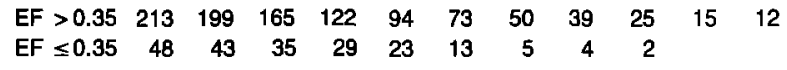

Fig. 5. Effect of ejection fraction (EF) on survival in 261 hospital survivors aged 80 years and older undergoing AVR. Number at risk shown by year.

tant complications of surgery in this age group. However, we found no correlation between these events and a history of cerebrovascular or peripheral vascular disease. Others have shown that aortic calcification, older age, perioperative hypotension, and prolonged bypass time are important determinants of perioperative strokes. ${ }^{25}$ Inasmuch as most cerebral events are thought to be embolic, careful aortic cannulation, removal of loose calcific debris in the aorta, removal of air, and minimal reclamping of the aorta should be important aspects of the operation in this age group. Maintenance of adequate perfusion pressure during cardiopulmonary bypass $(>60 \mathrm{~mm} \mathrm{Hg}$ ), particularly in patients with known cerebrovascular disease, is most probably important. The role of systemic hypothermia versus normothermic perfusion remains a subject of controversy. ${ }^{26,27}$ However, recent data suggest that systemic hypothermia is likely to be more cerebroprotective than normothermia. ${ }^{26}$

Whether to perform CABG at the same time as AVR is a question that many investigators have attempted to address. ${ }^{14,28}$ In this series, 34 patients had coronary artery disease that was not grafted, and four of them died (11.8\%). Although the mortality of patients undergoing $\mathrm{CABG}$ was significantly greater than that for those who did not have CABG, we believe that coronary arteries with significant stenoses should be grafted if possible. An earlier study from our own institution has shown that patients who have unrecognized and ungrafted coronary artery disease at the time of AVR may be at significant risk for a perioperative myocardial infarction or death. ${ }^{14}$ Although in that early series a significant number of patients did not undergo preoperative coronary angiography, particularly in 
the absence of angina, ${ }^{14}$ we now believe that angiography should be undertaken in all patients. However, invasive assessment of the valve is not essential if the clinical symptoms, physical examination, and results of two-dimensional echocardiography are all indicative of significant aortic valve disease. ${ }^{13}$

The long-term results of AVR are clearly better than the results of untreated aortic stenosis. The long-term survival, which is equivalent at least to that of an age- and sex-matched population, probably indicates in part a process by which both cardiologists and surgeons have selected suitable candidates for surgery. The improvement in quality of life further emphasizes the value of surgical treatment in this particular age group. We believe that successful treatment probably results in fewer subsequent admissions to the hospital for repeated management of heart failure or angina. This is likely to result in significant cost savings, particularly in an era of increasing scarcity of health care dollars.

We acknowledge contributions to patient care by Dr. Gordon Danielson, Dr. Francisco Puga, Dr. Christopher McGregor, Dr. Jeffrey Piehler, Dr. James Pluth, and Dr. R. Michael King and careful typing of the manuscript by Kathy Distad.

\section{REFERENCES}

1. US Bureau of the Census. Statistical abstract of the United States: 1994, ed 109. Washington DC: US Government Printing Office, 1994.

2. US Bureau of the Census. Major improvement in life expectancy: 1989. Statistical bulletin. July-September 1990. Washington, DC: US Bureau of the Census, US Government Printing Office, 1990.

3. Elayda MA, Hall RJ, Reul RM, et al. Aortic valve replacement in patients 80 years and older: operative risks and long-term results. Circulation 1993;88(5 Pt 2):II11-6.

4. Culliford AT, Galloway AC, Colvin SB, et al. Aortic valve replacement for aortic stenosis in persons aged 80 years and over. Am J Cardiol 1991;67:1256-60.

5. Deleuze P, Loisance DY, Besnainou F, et al. Severe aortic stenosis in octogenarians: Is operation an acceptable alternative? Ann Thorac Surg 1990;50:226-9.

6. Levinson JR, Akins CW, Buckley MJ, et al. Octogenarians with aortic stenosis: outcome after aortic valve replacement. Circulation 1989;80(3 Pt 1):I49-56.

7. Fiore AC, Naunheim KS, Barner HB, et al. Valve replacement in the octogenarian. Ann Thorac Surg 1989;48:104-8.

8. Pasic M, Carrel T, Laske A, et al. Valve replacement in octogenarians: increased early mortality but good long-term result. Eur Heart J 1992;13:508-10.

9. Olsson M, Granstrom L, Lindblom D, Rosenqvist M, Ryden L. Aortic valve replacement in octogenarians with aortic stenosis: a case-control study [Abstract]. J Am Coll Cardiol 1992;20:1512-6.

10. Kleikamp G, Minami K, Breymann T, et al. Aortic valve replacement in octogenarians. J Heart Valve Dis 1992;1:196200.

11. Azariades M, Fessler CL, Ahmad A, Starr A. Aortic valve replacement in patients over 80 years of age: a comparative standard for balloon valvuloplasty. Eur J Cardiothorac Surg 1991;5:373-7.

12. Tsai TP, Matloff JM, Chaux A, et al. Combined valve and coronary artery bypass procedures in septuagenarians and octogenarians: results in 120 patients. Ann Thorac Surg 1986;42:681-4.

13. Roger VL, Tajik AJ, Reeder GS, Hayes SN, Mullany CJ, Bailey KR, et al. Effect of Doppler echocardiography on utilization of hemodynamic cardiac catheterization in the preoperative evaluation of aortic stenosis. Mayo Clin Proc 1996;71:141-9.

14. Mullany CJ, Elveback LR, Frye RL, et al. Coronary artery disease and its management: influence on survival in patients undergoing aortic valve replacement. J Am Coll Cardiol 1987; 10:66-72.

15. Ross J Jr, Braunwald E. Aortic stenosis. Circulation 1968; 38(Suppl):V61-7.

16. Frank S, Ross J Jr. Natural history of severe acquired valvular aortic stenosis [Abstract]. Am J Cardiol 1967;19:128.

17. Dancy M, Dawkins K, Ward D. Balloon dilatation of the aortic valve: limited success and early restenosis. Br Heart J 1989;60:236-9.

18. Litvack F, Jakubowski AT, Buchbinder NA, Eigler N. Lack of sustained clinical improvement in an elderly population after percutaneous aortic valvuloplasty. Am J Cardiol 1988;62: $270-5$.

19. Freeman WK, Schaff HV, Orszulak TA, Tajik AJ. Ultrasonic aortic valve decalcification: serial Doppler echocardiographic follow-up. J Am Coll Cardiol 1990;16:623-30.

20. Pellikka PA, Nishimura RA, Bailey KR, Tajik AJ. The natural history of adults with asymptomatic, hemodynamically significant aortic stenosis. J Am Coll Cardiol 1990;15: 1012-7.

21. Piehler JM, Danielson GK, Pluth JR, et al. Enlargement of the aortic root or anulus with autogenous pericardial patch during aortic valve replacement: long-term follow-up. J Thorac Cardiovasc Surg 1983;86:350-8.

22. Nicks R, Cartnill T, Bernstein L. Hypoplasia of the aortic root: the problem of aortic valve replacement. Thorax 1970; 25:339-46

23. Fremes SE, Goldman BS, Ivanov J, Weisel RD, David TE, Salerno T. Valvular surgery in the elderly. Circulation 1989; 80(3 Pt 1):I77-90.

24. Morris JJ, Schaff HV, Mullany CJ, et al. Determinants of survival and recovery of left ventricular function after aortic valve replacement. Ann Thorac Surg 1993;56:22-30.

25. Gardner TJ, Horneffer PJ, Manolio TA, et al. Stroke following coronaty artery bypass grafting: a ten-year study. Ann Thorac Surg 1985;97:574-81.

26. Martin TD, Craver JM, Gott JP, et al. Prospective, randomized trial of retrograde warm blood cardioplegia: myocardial benefit and neurologic threat. Ann Thorac Surg 1994;57:298304.

27. The Warm Heart Investigators. Randomized trial of normothermic versus hypothermic coronary bypass surgery. Lancet 1994:343:559-63.

28. Bonow RO, Kent KM, Rosing DR, et al. Aortic valve replacement without myocardial revascularization in patients 
Volume 111, Number 5

with combined aortic valvular and coronary artery disease. Circulation 1981;63:243-51

\section{Discussion}

Dr. Aurelio Chaux (Los Angeles, Calif.). Given the fast growth of the population 80 years and older, it is important to continue to collect information regarding the results of cardiac surgery and the determinants of outcomes in this group. In this review, the authors have reiterated that acute symptoms such as rest pain indicate that surgery should be performed on an urgent or emergency basis. They also reiterate that female gender, low ejection fraction, renal impairment, and the presence of mitral valve disease are important predictors of operative mortality. The hospital mortality of $13.7 \%$ reported by the authors is three times higher than the mortality reported last year by our group, and female gender was very significant in their series. This leads me to my first question. Do you think that the frequent use of aortic root enlargement, particularly in women, has some effect on this mortality? We rarely use this operation and would prefer, if there is no contraindication to warfarin sodium, to implant a mechanical prosthesis. I noticed a correlation, not only with female gender, but also with small size valve. Can you provide more information regarding the results in this subgroup of patients in which aortic root enlargement was performed.

Dr. Gehlot. At the Mayo Clinic there is a low threshold for doing aortic annular enlargement with a pericardial patch. Thirty-eight patients required aortic annular enlargement so that a larger size valve could be inserted. In addition, enlargement of the aortic root makes it easier to close the aortotomy. Of 38 patients who had annular enlargement, six died.

Dr. Chaux. One of the important contributions of this review is to provide information regarding the long-term outcomes. Your mean follow-up is a very respectable 46 months. In the univariate analysis, factors that adversely affected the long-term survival were male sex, concomitant CABG, presence of two comorbidities, and low ejection fraction. I was surprised by the fact that in a multivariate analysis none of the factors remained significant according to your manuscript. I wonder if the reason for this is that when you performed the multivariate analysis, you tested only those that were statistically significant and not all of the factors that were analyzed in the univariate analysis.

Dr. Gehlot. All the factors that were significant on univariate analysis for long-term survival were entered into the Cox regression analysis. By entering them into a forward or backward model, we found a different factor that came up significant in each model. Therefore, none of the factors was consistently significant on multivariate analysis.

Dr. Chaux. I think to do the multivariate analysis you should include all of the factors, not just the ones that were significant in the univariate analysis. We have always found, for instance, that age continues to be a significant factor that influences the long-term results of the patient.

In the manuscript you state that only $56 \%$ of patients have preoperative cardiac catheterization. Do you mean that only $56 \%$ had invasive hemodynamic evaluation? If so, did all patients have preoperative coronary angiography?

Dr. Gehlot. Of the 322 patients, 300 patients had an estimate of their left ventricular ejection fraction by cardiac catheterization or echocardiography or both. There were 221 patients who had an echocardiogram and there were 172 patients who had cardiac catheterization with left ventriculography.

Dr. Chaux. Did all patients have coronary angiography?

Dr. Gehlot. I believe that there were a few patients during the early years of our experience who did not have coronary angiography.

Dr. Chaux. How can you estimate the incidence of coronary artery disease in this population if you do not know preoperatively what the coronary anatomy is?

Dr. Gehlot. The great majority of the patients had coronary angiography before the operation.

Dr. Chaux. Do you agree that there are three different types of patient populations that should be analyzed separately, namely, those with isolated aortic valve disease, those with primarily aortic valve disease and incidental coronary artery disease, and those with primarily coronary artery disease and incidental findings of aortic valve disease? In our experience, if we analyze the results in this way, these results are entirely different.

Dr. Gehlot. You are correct. The paper we have presented considers anyone who has had an AVR, including those with coexisting coronary artery disease or mitral valve disease. However, we do not have information on which patients were primarily investigated for coronary artery disease and found to have incidental aortic valve disease. Valve mortality for isolated AVR was approximately $8 \%$.

Dr. Chaux. Finally, the survival curves that you have presented eliminated the hospital mortality. Don't you think that, in trying to determine survival in this patient population, this is an important factor that should be included in the analysis? I think that it is misleading to eliminate hospital mortality from consideration when advising our elderly patients as to whether they should have an operation or not. Do you agree or disagree?

Dr. Gehlot. When we are discussing the operation with a patient, he or she is interested in what the surgical risk is. If the operation is successful, we are able to explain to the patient what the long-term outlook is expected to be This is why we have presented the data in this fashion.

Dr. Chaux. If you are going to do that, you have to be very clear and explicit about the reasons why you eliminated the hospital mortality from the analysis.

Dr. John V. Redington (Torrance, Calif.). Dr. Gehlot, have you addressed the issue of extensive ascending aortic atherosclerosis? We are seeing this comorbidity more frequently in this patient population. It has forced me to do AVR with deep hypothermia and circulatory arrest with retrograde cerebral perfusion. Do you have a subpopulation with extensive ascending atherosclerosis? What has your strategy been in handling that phenomenon in the octogenarian population?

Dr. Gehlot. We did not specifically evaluate aortic atherosclerosis as a comorbid factor. However, we did attempt to see what risk factors were present in the 27 patients who had a postoperative cerebrovascular acci- 
dent. Diabetes, peripheral vascular disease, known preoperative cerebrovascular disease, and preoperative abdominal aneurysm did not have any relationship to the development of postoperative stroke.

Dr. Redington. Have you used deep hypothermia and circulatory arrest in any octogenarian patients with profound ascending aortic atherosclerosis?

Dr. Gehlot. There were one or two patients who had surgery with deep hypothermia and total circulatory arrest.

Dr. Redington. Your impression, then, is that at least aortic embolic events have not been an identifiable cause of cerebrovascular accidents in your population.

Dr. Gehlot. In general, most cerebrovascular events after cardiac surgery are thought to be embolic in nature. We believe careful handling of the tissues, including aortic cannulation, removal of all calcific debris, and evacuation of air at the completion of the procedure are important aspects of the operation.

Dr. Redington. That is rather the point of my question. One would have to suspect that atheroembolic events from the ascending aorta in this population would be a substantial contributor to cerebrovascular accidents and therefore morbidity and mortality.

Dr. Gehlot. You are correct that aortic atheroemboli are believed to be an important cause of perioperative stroke. This is a large series over many years and we do not have enough information about the state of the aorta in all of these patients.

Dr. R. Scott Mitchell (Stanford, Calif.). Dr. Stinson at our institution looked at a similar cohort of elderly patients and saw also that the extent of age was significantly ameliorated by comorbidities. One of the comor- bidities that was very significant was obstructive pulmonary disease, which did not achieve significance in your paper. Can you comment about that difference? Our patients with chronic obstructive pulmonary disease, renal insufficiency, and decreased ejection fractions all had significant increases in operative mortality. You did not find that in your patients.

Dr. Gehlot. Patients with chronic obstructive pulmonary disease had a mortality of $21.5 \%$ compared with $11.7 \%$ for those without this disease. However, on multivariate analysis this was not significant.

Dr. Mitchell. Do you have any information about the length of stay for this hospital cohort?

Dr. Gehlot. The median length of stay in this population was 11 days.

Dr. Colleen F. Sintek (Los Angeles, Calif.). I rise to offer an alternative to aortic root enlargement or to placement of a mechanical prosthesis in this age group of patients. At our institution for the past $2 \frac{1}{2}$ years we have been using the stentless porcine aortic root supplied by Medtronic, Inc., the Freestyle valve. In this group of patients, we have found excellent hemodynamics in the small valve sizes, even sizes 19 and 21, with very low transvalvular gradients. We have used the freehand technique, leaving the noncoronary sinus portion of the Freestyle valve intact. The valve is fairly easy to insert, the technique is less demanding than an aortic root enlargement procedure, and one can use the retained noncoronary sinus portion of the Freestyle valve to augment that portion of the aortotomy or to reinforce it so that it does not bleed.

Dr. Gehlot. We have used the stentless valve, but not in this age group. We do not believe that this is a device that should be used routinely for the small aortic root. 